\title{
A INFLUÊNCIA DOUTRINÁRIA FRANCESA SOBRE OS MILITARES BRASILEIROS NOS ANOS DE 1960
}

\author{
João Roberto Martins Filho
}

Os estudiosos da história política brasileira entre o final dos anos de 1950 e o final da década de 1970 constantemente se deparam nos textos militares com duas expressões a que não atribuem muita importância: "guerra revolucionária" e "defesa da civilização cristã". Contudo, esses termos são ricos de significado, uma vez que remetem à matriz do pensamento militar que vigorou durante pelo menos duas décadas e marcou profundamente a visão de mundo de uma geração de oficiais, principalmente do Exército brasileiro. Durante muito tempo a literatura sobre essa fase histórica concentrou-se na chamada Doutrina da Segurança Nacional, elaborada pela Escola Superior de Guerra (ESG), a partir de finais dos anos de 1940. A essa doutrina atribui-se forte influência norte-americana. Em contraste, a doutrina francesa da guerre révolutionnaire, introduzida na ESG em 1959, não foi até hoje analisada em profundidade. ${ }^{1}$

Artigo recebido em abril/2007

Aprovado em abril/2008
Comblin e o poder militar na América Latina

O exemplo mais acabado de tal concepção é o livro do padre e professor de teologia em Harvard, Joseph Comblin - A ideologia da segurança nacional, publicado originalmente em francês, em 1977 (Comblin, 1980). Destinado a ter grande influência sobre a literatura relativa às ditaduras militares do Cone Sul, o texto é uma narrativa que acaba por simplificar em demasia a questão dos influxos doutrinários que alimentaram os golpes militares dos anos de 1960 e 1970.

Sua tese central é simples: "É incontestável" que a doutrina que inspirou os golpes militares "vem diretamente dos Estados Unidos. É nos Estados Unidos que os oficiais dos exércitos aliados aos EUA aprendem-na" (Idem, p. 14). No decorrer do livro, fica claro que para Comblin o processo histórico de construção da mentalidade ditatorial é elementar. Segundo ele, os chefes militares latinoamericanos não tinham - e nem precisavam ter - 
idéia do tipo de sociedade e de governo que iriam fundar, e sequer sabiam que iriam criar um novo regime. O que importava eram os processos objetivos, vale dizer, "a coesão e a força dos fatores históricos que estavam em ação, a coesão e a força do modelo de segurança nacional", que "se realiza, de certo modo, por si mesmo, graças a seu dinamismo interno: utiliza os generais e seus conselheiros civis e os leva a fazer coisas com as quais jamais haviam sonhado". Nessa mecânica, "toda a força do sistema forjado nos Estados Unidos entra em ação" (Idem, p. 71).

Tal explicação dispensa o estudo dos processos internos de construção da mentalidade militar. Na verdade, na visão de Comblin, os setores militares que apoiaram os golpes aparecem como uma simples marionete ideológica, sem história política ou capacidade de gerar seus próprios mitos, doutrinas ou ideologias. Há alguns problemas básicos nesse tipo de explicação. Em primeiro lugar, ela parte de uma definição excessivamente genérica do ideário da segurança nacional, tanto na forma como foi construído nos Estados Unidos, no início da Guerra Fria, como na forma que tomou nas escolas de guerra de países como Brasil e Argentina. Além disso, essa análise tende a perder especificidades nacionais dos processos de construção do golpismo militar, as quais tiveram conseqüências importantes na própria configuração das ditaduras que se seguiram. Assim, tudo se passa como se a importação da ideologia da segurança nacional explicasse por si só o aparecimento de Estados de segurança nacional, cuja coesão interna tivesse sido garantida pela doutrina que lhes deu origem. Para alguns autores, a raiz dessa confusão estaria na própria indistinção, presente no livro de Comblin, entre ideologia e doutrina. No sentido em que a usamos aqui, doutrina significa

[...] um conjunto de ensinamentos, com freqüência um conjunto de princípios ou um credo. No jargão militar, usa-se tipicamente doutrina num sentido mais limitado, para referir-se a princípios estratégicos ou táticos particulares, como a doutrina de retaliação maciça. Por outro lado, define-se comumente ideologia como um conjunto generalizado de idéias políticas, uma visão de mundo, como o liberalismo e o comunismo. Tratar doutrina, especialmente doutrina militar, e ideologia, como termos mais ou menos intercambiáveis obscurece a questão da relação entre os dois (Fitch, 1998, pp. 107 e 110).
Finalmente, há na análise uma proposta de periodização. Para o autor, “1961/1962 são os anos em que o conceito (de guerra revolucionária) inicia sua carreira triunfal nas Américas" (Comblin, 1980, p. 44). Mais adiante, ele afirma que essa "estratégia contra-revolucionária [...] serviu sobretudo para formar uma escolástica militar rígida, um manual de guerra revolucionária, que se tornou, desde 1961, a base do ensinamento dado aos exércitos latinoamericanos" (Idem, p. 47).

\section{A guerre révolutionnaire}

Pelo menos no caso das Forças Armadas de dois dos mais importantes países latino-americanos, Brasil e Argentina, as coisas não se passaram assim. Se marcarmos a data de nascimento da era kennediana da contra-insurreição em 18 de janeiro de 1962, quando o presidente promulgou o Memorando de Ação de Segurança Nacional 124 (NSAM-124), podemos afirmar que, nessa data, alertar os militares argentinos e brasileiros para a urgência de desenvolver uma doutrina de combate à guerra subversiva seria o mesmo que ensinar o Padre-Nosso ao vigário. Antes mesmo do triunfo da Revolução Cubana, os oficiais daqueles países tinham buscado, por conta própria, uma doutrina de guerra mais adaptada às suas necessidades, que os Estados Unidos não pareciam em condições de oferecer.

No processo de importação das idéias francesas, o pioneirismo coube à Argentina. Como mostrou Ernesto López, o então coronel Carlos J. Rosas, que acabava de regressar da França, assumiu em 1956 a subdireção da Escuela Superior de Guerra, em Buenos Aires, dando início a um processo de redefinição doutrinária calcado nos ensinamentos de veteranos franceses da Indochina e da Argélia. Em 1957, o referido oficial trouxe para a ESG argentina, na qualidade de professores e assessores da direção, quatro militares com experiência nas guerras coloniais: os tenentes-coronéis Badie, de Naurois, Bentresque e Nougues, que ali permaneceram até 1962 (López, 1988, pp. 137-138). Entre 1958 e 1959, a Revista de la Escuela Superior de Guerra publicaria uma série de artigos de autoria desses assessores e de um grupo de oficiais argentinos que havia estagiado na Europa, cujo tema central era a doutrina da guerre révolutionnaire (Idem, p. 144). 
No caso do Brasil, o coronel Augusto Fragoso pronunciou em maio de 1959 no curso de EstadoMaior e Comando da Escola Superior de Guerra a palestra "Introdução ao estudo da guerra revolucionária", fruto aparentemente de seus próprios estudos diretos da produção francesa, que evidentemente começaram algum tempo antes. O contexto mais geral em que se deu a entrada dessas idéias no Brasil é lembrado pelo general Octavio Costa:

\begin{abstract}
Nesse momento, estávamos profissionalmente perplexos, sem saber que direção tomar. [.. . ] Então começamos a tomar conhecimento de novas experiências [...]. Nessa ocasião, a literatura militar francesa [.. .] começa a formular um novo tipo de guerra. Era a guerra infinitamente pequena, a guerra insurrecional, a guerra revolucionária. [...] Isso entrou pelo canal da nossa ESG, e foi ela que lançou as idéias sobre as guerras insurrecional e revolucionária e passou a nelas identificar o quadro da nossa própria possível guerra. Para nós ainda não havia guerra nuclear, a guerra convencional já estava ultrapassada. Mas havia uma guerra que nos parecia estar aqui dentro. [...] Isso tudo contribuiu para a formulação da nossa própria doutrina da guerra revolucionária, que resultou no movimento militar de 64 (D'Araujo et al., 1994, pp. 77-78). ${ }^{2}$
\end{abstract}

No final dos anos de 1950, antes mesmo da eclosão da Revolução Cubana, os franceses eram os únicos a tratar do tema da guerra revolucionária. Desde meados dessa década, após a fragorosa derrota em Dien-Bien-Phu e a eclosão da rebelião na Argélia, fortaleceu-se no Exército francês a idéia de que a razão da derrocada na Indochina fora o fato de que a doutrina militar não estava preparada para enfrentar um novo tipo de guerra. A principal característica desta forma de conflito era a indistinção entre os meios militares e os não militares e a particular combinação entre política, ideologia e operações bélicas que ela proporcionava. Nesse quadro, a nova doutrina "oferecia um diagnóstico e um remédio para aquilo que um influente grupo de militares de carreira franceses via como a doença principal do mundo moderno - a falência do Ocidente em enfrentar o desafio da subversão comunista atéia" (Shy e Collier, 1986, p. 852). ${ }^{3}$

Por outro lado, mesmo depois do surgimento da doutrina norte-americana da contra-insurreição, o Exército dos Estados Unidos não podia ocupar na mesma medida a condição de role model gozada pelos oficiais franceses junto a seus colegas argenti- nos e brasileiros. Isso, em primeiro lugar, porque a doutrina norte-americana do começo dos anos de 1960 nunca deixou de ser um artigo de exportação e de restrito consumo interno no interior das Forças Armadas dos Estados Unidos, apesar da obsessão de Kennedy pelo tema. Por sua vez, o aparelho de Estado civil não contava com agências como os serviços coloniais britânicos e franceses, indispensáveis para integrar os aspectos políticos e militares da guerra revolucionária.

O Exército dos Estados Unidos "desconfiava de um grupo treinado para operações irregulares", o que se expressou anos depois, no Vietnã, nos desencontros entre essas tropas - que operavam em estrito contacto com a Central Intelligence Agency - e o comando do Exército. O Exército francês, ao contrário, instalou a guerre révolutionnaire no centro de seu pensamento militar e de sua doutrina operacional. Como reconhecem dois especialistas norte-americanos, um deles ex-oficial no Vietnã, "no seio do corpo de oficiais franceses, surgiu uma preocupação obsessiva no sentido de aprender as lições da guerra da Indochina, de modo que as futuras guerras revolucionárias, já iminentes em outras partes do Império Francês, pudessem ser vencidas" (Idem, p. 852).

Em segundo lugar, e talvez mais importante, um dos pressupostos fundamentais da doutrina francesa era a idéia de que, se o controle das informações é o elemento decisivo da guerra revolucionária, seria impossível combater esse tipo de inimigo sem um comando político-militar unificado. Assim, essa doutrina entra no campo das relações civis-militares. Ao fazê-lo, não hesita em afirmar que, se a sociedade democrática é incapaz de fornecer ao Exército o apoio necessário, então seria preciso mudar a sociedade, não o Exército. $\mathrm{Na}$ expressão de um de seus principais teóricos, o comandante Hogard, "é tempo de perceber que a ideologia democrática tornou-se impotente no mundo atual" (Paret, 1964, p. 28).

Em outras palavras, a doutrina da guerre révolutionnaire trazia subjacente um projeto de intervenção militar na sociedade - que resultaria nas crises militares de 1958, 1960, 1961 e 1962. Não por acaso, um autor como Peter Paret, escrevendo na primeira metade dos anos de 1960, encontrava nos escritos do general Lyautey, datados de 1891, o "anseio por uma elite regeneradora, que testa e prova a si própria no serviço militar antes de liderar sua 
nação rumo a uma nova grandeza" (Idem, p. 108). Uma mensagem que devia soar como música aos ouvidos das correntes militares conservadoras, no Brasil e na Argentina do final da década de 1950. Trocando em miúdos, enquanto os militares e civis norte-americanos pareciam dizer "façam o que digo e não o que eu faço", a doutrina francesa rezava simplesmente "façam o que digo $e$ o que eu faço".

Há ainda outro aspecto relevante. Em exércitos como os da Argentina e do Brasil nos anos de 1950, envolvidos cada um à sua maneira na criação de uma ideologia militar abrangente e ambiciosa, caía como luva o exemplo francês dos intelectuais militares que pensavam por conta própria, em pé de igualdade com seus colegas e aliados civis, que de resto nunca faltaram. Não menos importante, o romantismo e a mística quase religiosa que acompanhavam a doutrina francesa também funcionaram como atrativo adicional para oficiais em busca de uma missão para seus exércitos, no apogeu da Guerra Fria.

Enfim, a doutrina militar francesa oferecia aos militares de nossos países uma definição flexível e funcional do inimigo a enfrentar, ao mesmo tempo em que, no plano geopolítico, valorizava o Terceiro Mundo como cenário do confronto mundial da Guerra Fria. Afinal, ocupava o centro dessa doutrina a idéia de que, "enquanto os Estados Unidos e seus aliados estavam hipnotizados pela perspectiva da guerra nuclear, o comunismo flanqueava as defesas do Ocidente a partir do Sul, e se não fosse contido destruiria, ao fim, a civilização ocidental" (Shy e Collier, 1986, p. 852).

Nesse quadro, o inimigo era definido de forma ampla o suficiente para servir às mais variadas situações nacionais. A idéia geral era de que a civilização cristã estava envolvida numa guerra permanente e mundial, em que as distinções tradicionais entre guerra e paz passavam a ser insignificantes, assim como na expressão de um analista - as diferenças entre anticolonialismo, nacionalismo anti Ocidente e comunismo. Vale dizer, o esquema francês era genérico o suficiente tanto para permitir que o Exército argentino definisse como seu principal inimigo o peronismo, que nada tinha a ver com o comunismo, como para dar ao Exército brasileiro uma justificação a mais para combater os nacionalistas ou os católicos radicais, além dos comunistas de várias feições.

Faz-se necessário, então, entender em que consistia, em linhas gerais, tal doutrina. Para usar a definição do sociólogo Raoul Girardet, essa seria "uma doutrina internacional capaz de efetivamente se opor às teorias marxistas-leninistas [. . .] um sistema de valores suficientemente forte para unir e estimular as energias nacionais" (Apud Paret, 1964, p. 27). O coronel Georges Bonnet resume a questão numa fórmula simples: "guerra partisan + guerra psicológica = guerra revolucionária". Trata-se, assim, de uma doutrina que extraía seu nome do fenômeno que visava combater - a guerra revolucionária. Esta, por sua vez, é definida por Girardet como "uma doutrina de guerra exposta pelos teóricos marxistasleninistas e explorada por movimentos revolucionários de várias tendências" (Apud Paret, 1964, p. 143).

Esse efeito de espelho é uma das características mais particulares da doutrina francesa. Para esta, a guerra revolucionária é diferente da guerra convencional porque coloca o recurso às armas no final e não no começo do conflito. Ela se constitui de um processo diversificado e prolongado, cuja evolução pode ser dividida em cinco etapas. A primeira seria a da preparação cautelosa do terreno que se pretende conquistar, ou seja, a população. Nessa etapa, os militantes agem sem declarar seus objetivos. A segunda fase se expressa na constituição de uma rede de organizações subversivas, controladas pelos militantes. Nesse estágio, formam-se bases que subvertem a capacidade de ação governamental. Surgem as manifestações, os tumultos e os atos de sabotagem.

A terceira etapa é marcada pela constituição de grupos armados, que iniciam ações de menor escala, destinadas a corroer os poderes constituídos. É a fase do terrorismo como principal método de ação. A penúltima etapa é a do estabelecimento de zonas liberadas ou bases d'appui, onde o Exército regular não consegue mais entrar, ao que se segue a formação de um governo provisório que procura reconhecimento externo. Forma-se um exército regular revolucionário. A quinta etapa significa a conquista do poder numa ofensiva final. É fundamental notar que essas fases se sucedem muitas vezes sem fronteiras nítidas, pois a fluidez seria a principal característica da guerra revolucionária. De todo modo, a doutrina fornecia uma régua com a qual se podia medir o agravamento da ameaça revolucionária (Paret, 1964, pp. 12-15). O único modo de evitar a progressão desse processo seria derrotar os revolucionários com suas próprias armas. Assim, no centro da doutrina da guerre révolutionnaire aparece a idéia de guerra psicológica (Idem, pp. 21-25). 


\section{A conexão francesa}

Os dois anos finais do governo Juscelino Kubitscheck foram de intensa atividade na Escola Superior de Guerra. Como registrou um historiador dessa instituição, "o estudo da Guerra Revolucionária, na ESG, teve início em 1959, através de uma conferência do então coronel Augusto Fragoso, que a reproduziu, em termos semelhantes, porém ampliados, no ano seguinte, já como general e assistente do comando" (Arruda, 1980, p. 245). De nossa perspectiva, essa aula pode ser considerada um marco divisório, na medida em que estabelece um ponto final no período de indefinição no debate sobre as formas de guerra na ESG. Sua idéiaforça foi a tese de que os militares brasileiros deviam concentrar-se, daí em diante, num "novo" tipo de guerra: "hoje, o estudo da guerra revolucionária deve merecer, mormente em países em desenvolvimento como o nosso - importância paralela, quando não maior, ao da guerra nuclear. É sob a forma de GR - afirma o Cel Lacheroy - que o destino do mundo se decide na hora atual, e vai se decidir nos próximos 20 anos!" (Estado-Maior das Forças Armadas, 1959, p. 12). E, mais adiante: "Ao estudo da GR, muito mais que ao da chamada guerra nuclear total, mormente nos países subdesenvolvidos, deve se dar a máxima importância” (Idem, p. 48).

Em seu aspecto mais geral, a aula do coronel Augusto Fragoso constituiu-se numa apresentação da literatura francesa sobre a guerra revolucionária, sem menção aos estudos que se faziam à época na Argentina. Suas fontes principais são o documento Contribution a une étude sur la guerre révolutionnaire, publicado pela Escola Superior de Guerra de Paris (1955-1956); os livros do coronel Gabriel Bonnet, Les guerres insurrectionelles et révolutionnaires (1958); ${ }^{4}$ de Pierre Debray, La Troisiéme Guerre Mondiale (1958); de Claude Delmas, La guerre révolutionnaire (1959) e artigos de J. Hogard, Lacheroy, Ximenes, Berteil, Cailloux, Renaud e outros, que vieram à luz nas revistas militares francesas, além de uma edição em francês da obra de Mao Tsé-tung, Os problemas estratégicos da guerra revolucionária na China ([1936] 1957).

A exposição de Fragoso inicia-se com uma tentativa de distinção entre guerra insurrecional e guerra revolucionária, na qual, com base em J. Hogard, ele define que a GR é: 1) "a guerra da Revolução para a conquista do mundo", enquanto as GIs podem se restringir a um país, e 2) a GR tem uma doutrina: a marxista leninista, ao passo que as GIs “tem processos empíricos”. Seu marco histórico seria a Revolução Chinesa de 1949 e seu teórico principal, Mao Tsé-tung. Ainda com base em Hogard, Fragoso enfatiza a ruptura da GR com a guerra clássica, na medida em que a primeira não seria puramente militar e, em vez de ser uma continuação da política, funcionaria como um apoio da política.

Além disso, a GR, segundo Fragoso, tem um caráter basicamente insidioso e subliminar, apresentando como elemento-chave a atuação sobre as idéias, vale dizer, a ação psicológica. Citando Bonnet, o coronel brasileiro retorna à já citada fórmula que define a GR como uma combinação entre guerra partisan e guerra psicológica. Ela seria uma guerra particular, na medida em que seu meio principal, seu objetivo e sua arma mais importante recairiam sobre a própria população do país-alvo. Nesse sentido, não haveria GR sem a atuação de uma minoria militante e organizada e, em geral, sem o apoio externo. A GR tem duas fases: a destrutiva, centrada na dissolução física e moral do corpo social, e a construtiva, na qual surge a sociedade totalitária. Enfim, Fragoso retoma de Hogard o esquema já citado das cinco fases.

$O$ aspecto que mais nos interessa na palestra de 1959 é a tentativa de inserir o Brasil no quadro geral da guerra revolucionária mundial. Com base em C. Montirian, a idéia que percorre todo o texto é a de que a GR atua em círculos cada vez maiores, que se afastam das fronteiras dos países socialistas. Nessa dinâmica teria soado a hora da América Latina. Voltando ao esquema da Hogard, Fragoso lembra que a GR pode ser dividida em duas fases maiores: a pré-revolucionária, ou clandestina, e a revolucionária, ou ostensiva. A primeira fase é a mais perigosa, porque nela as instituições vêem-se despreparadas para enfrentar a ameaça subversiva. $\mathrm{Na}$ visão do coronel Fragoso, o Brasil do final dos anos de 1950 já viveria o estágio pré-revolucionário (Estado-Maior das Forças Armadas, 1959, p. 48). A partir de uma leitura particular de documentos partidários, o texto da ESG vê na estratégia pacifista e legalista do Partido Comunista a ante-sala da revolução violenta, distinguindo-se apenas por seu caráter subliminar, em que se procura arregimentar o movimento nacionalista para a Revolução.

Nesse quadro, seria impossível escapar à conclusão de que algo precisava ser feito a fim de 
preparar o Estado e as Forças Armadas para enfrentar a ameaça do inimigo interno. O problema é que as autoridades responsáveis, "em face do direito", não dispunham "senão de campo de iniciativa muito limitada quanto à escolha das técnicas e dos meios legais a aplicar, enquanto os revolucionários consideram válidos todos os meios imagináveis de luta" (Idem, p. 22). Em tal contexto, haveria urgência "para combater a subversão, para enfrentar a guerra revolucionária, desde o seu período clandestino, de uma legislação adequada", na medida em que "não se pode manter em relação aos militantes da guerra revolucionária, o respeito das liberdades individuais asseguradas aos demais cidadãos e as medidas de proteção que beneficiam, na ação judiciária, os delinqüentes do direito comum". Diante disso, a conclusão de Fragoso é simples: "O regime democrático característico do mundo livre, e tão prezado por todos nós, não favorece, pelo abuso de liberdades que, via de regra, propicia ao adversário, nem a parada preventiva, nem a resposta enérgica" (Idem, p. 40).

Por sua vez, as Forças Armadas, "organizadas essencialmente em função das servidões da guerra clássica contra um inimigo exterior", enfrentam sérios obstáculos para adaptar, uma vez que eclode a violência, "sua organização para a luta contra o terrorismo urbano e os bandos guerrilheiros nos campos" (Idem, ibidem). A partir dessa situação, um dos problemas mais difíceis no combate à GR seria o papel a ser desempenhado diretamente pelas Forças Armadas. Algumas conclusões, no entanto, servem de ponto de partida: de um lado, é preciso criar serviços de informação capazes de antecipar os movimentos do inimigo interno; de outro, cabe às Forças Armadas construir uma organização de defesa interna do território, ao mesmo tempo em que cria unidades especialmente adestradas na luta anti-revolucionária. Porém, antes de tudo, é necessário reconhecer que a preparação para a guerra anti-subversiva supera as atribuições tradicionais das Forças Armadas. A ação contra-revolucionária exigiria uma iniciativa conjunta decidida por todos os poderes do Estado.

\section{A ação psicológica: o público interno}

Vale registrar que os estudos sobre o processo político-militar brasileiro dessa fase parecem perder aspectos fundamentais da evolução do qua- dro político das Forças Armadas. Mesmo trabalhos que se destacam pela importância que conferem à questão militar, centram-se basicamente em seus altos escalões, principalmente nos ministérios da Guerra, da Aeronáutica e da Marinha e nas chefias dos quatro exércitos. Ficam de fora, assim, os processos atuantes no campo em que, por excelência, se define a cultura militar dominante, isto é, as escolas de comando e o estado-maior, onde efetivamente se transmitem as idéias que perpassam toda a instituição e onde é possível medir a temperatura ideológica da organização militar.

No final da década de 1950, apesar do quadro de divisão militar evidenciado pela luta de personalidades e pelas disputas no Clube Militar, os corações e as mentes de parte relevante do Exército, da Marinha e da Aeronáutica começavam a pender decididamente para uma doutrina cujo desenlace natural era ou um governo civil que incorporasse as visões das Forças Armadas ou um golpe militar. Para entender esse processo, convém voltar à história especificamente militar do período.

É verdade que uma palestra na ESG não significava necessariamente o início de uma mudança doutrinária importante. Contudo, a conferência do coronel Augusto Fragoso teve conseqüências institucionais que não se pode deixar de considerar. Quatro meses depois, em 2 de setembro de 1959, o Chefe do Estado-Maior do Exército nomeou uma comissão para estudar a programação e a coordenação da instrução sobre guerra moderna, considerada então sob dois aspectos: guerra atômica e guerra insurrecional (Idem, p. 5). Há indícios de que esse processo começara antes na Marinha. De todo modo, a evolução iniciada no final do governo JK teve continuidade até que, em 27 de julho de 1961, sob o breve governo de Jânio Quadros, o EstadoMaior das Forças Armadas [EMFA] consolidou em doutrina as definições esboçadas dois anos antes. Nessa data, o general Oswaldo Cordeiro de Farias, então Chefe do EMFA, aprovou e recomendou a conceituação de guerra insurrecional, guerra revolucionária, de subversão (guerra subversiva), de ação psicológica, de guerra psicológica e de guerra fria, constante no documento FA-E-01/61 (EstadoMaior das Forças Armadas, 1961).

Já em sua primeira frase, o documento estabelecia que "a doutrina militar francesa enquadra três formas básicas de guerra" - convencional, nuclear e subversiva -, esclarecendo a seguir que 
era "vasta a literatura militar francesa sobre a última das três guerras acima". E continuava: "Sob o peso dos acontecimentos na Ásia e na África do Norte, os pensadores militares franceses tiveram necessidade de se embrenhar no conhecimento desta forma de guerra que, embora possuindo raízes profundas na História, passara a ostentar uma nova fronde, alimentada pela seiva que lhe foi ministrada, principalmente, por Karl Marx, Lenine e Mao Tse-Tung" (Idem, p. 1).

Segundo o mesmo texto, apesar de constituir "uma excelente fonte de estudo e de consulta", essa literatura ainda sentia falta de "uma terminologia básica uniforme", o que vinha dando margem a divergências, "algumas vezes sérias". O trabalho referia-se em seguida à doutrina militar norte-americana com sua definição de três formas de guerra convencional, nuclear e não convencional - apenas para concluir que "a literatura militar norte-americana proporciona parcos ensinamentos" sobre a última. Na continuação, a partir dos estudos da "literatura militar mundial, particularmente da francesa", efetuados pela comissão já mencionada, o documento expunha as idéias de vários autores, classificadas em dois grupos. As "doutrinárias" cotejavam, basicamente, as definições sobre guerra subversiva e guerra revolucionária, em autores como Boulnoie, Bonnet, Hogard, Étienne e Souyris, ao lado da documentação da Escola Superior de Guerra de Paris e de alguns autores norte-americanos. As "lexicológicas" compreendiam apenas as definições sobre insurreição, subversão e revolução encontradas nos principais dicionários da época. Em ambos os tópicos apareciam também definições de guerra fria, ação psicológica e guerra psicológica. A partir daí, o EMFA recomendava definir a guerra revolucionária nos seguintes termos:

É a guerra interna, de concepção marxista-leninista e de possível adoção por movimentos revolucionários diversos que - apoiados em uma ideologia, estimulados e, até mesmo, auxiliados do exterior - visam à conquista do poder através do controle progressivo, físico e espiritual, da população sobre que é desencadeada, desenvolvendo-se segundo um processo determinado, com a ajuda de técnicas particulares e da parcela da população assim subvertida (Idem, p. 21).

Em contraste, a guerra insurrecional era caracterizada como a guerra interna que obedecia a processos geralmente empíricos, vale dizer, não estava apoiada numa ideologia. A subversão (também chamada de guerra subversiva) corresponderia ao estágio pré-revolucionário ou de preparação da guerra revolucionária. Enfim, definia-se a ação psicológica como o conjunto de ações de caráter defensivo centradas na formação moral e cívica da população, a fim de fornecer-lhe meios de fazer frente à ofensiva da subversão ou da guerra psicológica. Esta era definida como o conjunto de ações de caráter ofensivo, com o alvo de minar a moral das tropas e da população inimiga.

Assim, seis meses antes do ato do governo Kennedy que inaugurou a era da contra-insurreição - o NSAM 124 -, o EMFA já dispunha de uma conceituação básica que orientaria a evolução posterior de sua doutrina da defesa interna. No plano doméstico, menos de um mês depois da publicação do documento do Estado-Maior brasileiro, a crise militar em torno da renúncia de Jânio Quadros, a resistência da Campanha da Legalidade e a posse de João Goulart contribuiriam para consolidar as visões que aqui vimos examinando. $\mathrm{Na}$ verdade, a renúncia apenas atrasou os planos em curso, no sentido de disseminação da doutrina da guerra revolucionária nas escolas de comando e Estado-Maior. O terreno para a semeadura já estava preparado pela publicação regular de artigos sobre o tema em periódicos de distribuição restrita aos estados-maiores de cada força, até aqui não mencionados na literatura. Entre estes se destacavam Mensário de Cultura Militar (a partir da edição final de 1965, Cultura Militar), Boletim de Cultura Militar e Boletim de Informações, todos de responsabilidade do Estado-Maior do Exército.

Em setembro de 1961, o Mensário lançou uma segunda edição especial - a primeira fora publicada em novembro/dezembro de 1960 - dedicada à temática da guerra revolucionária. O importante é notar que a publicação dos textos sobre a guerra revolucionária não apenas tinha a função de divulgar a doutrina, mas já configurava o exercício da ação psicológica, destinada, seguindo o exemplo dos $5^{\text {es }}$ Bureaux do Exército francês, a preparar ideologicamente as próprias forças, além de "assegurar a coesão do conjunto da nação e a desenvolver em cada um a vontade de lutar" (Paret, 1964, p. 57).

É essa a motivação mais geral do estágio sobre guerra revolucionária de agosto de 1962, do qual participariam noventa oficiais, principalmente 
do Exército. Na introdução ao novo número especial do Mensário, que publicou seu conteúdo (Estado-Maior do Exército, 1962), ${ }^{5}$ afirmava-se: "A importância da Ação Educacional e de Instrução contra a Guerra Revolucionária tem sido ressaltada pelo Estado-Maior do Exército, através de Diretrizes, Programas e Conferências, com o objetivo de preparar o Exército, psicológica e materialmente para opor-se a qualquer tipo de ação subversiva". Ao mesmo tempo, salientava-se que as Forças Armadas estavam "alertas e vigilantes, irmanadas pelo mesmo ideal democrático", mas era "imprescindível que estejam esclarecidas sobre as bases da ideologia comunista e sobre os processos e técnicas utilizados para a consecução de seus objetivos". Nesse quadro, o objetivo desse tipo de estágio seria elevar o padrão de instrução, "com a criação de reflexos e atitudes adequadas".

Aparentemente, o conteúdo foi baseado nos ensinamentos do Primeiro Curso de Guerra Contra-Revolucionária a que oficiais brasileiros assistiram na Argentina, em outubro de 1961, juntamente com colegas de outros treze países latino-americanos. No entanto, as aulas começam com a observação "coordenação e adaptação de" ou "coordenação e compilação de documentação existente no EME", o que supõe acréscimos nacionais. A palestra sobre guerra psicológica é uma exceção, pois, proferida por um almirante, baseia-se em textos norte-americanos. Por sua vez, a aula sobre "Guerra Revolucionária no Brasil" destina-se a lembrar a versão do Exército sobre a "Revolução de 1935 no Nordeste", tomada evidentemente como evidência das profundas raízes do comunismo no país. ${ }^{6}$

O estágio parece ter conseguido os objetivos almejados, pois foi repetido em 1963, com audiência ampliada e a participação de professores de filosofia civis, para aprofundar temas que fugiam à doutrina militar propriamente dita. Além disso, a documentação publicada naqueles periódicos era enviada "regularmente para os Estados-Maiores Regionais, servindo de base para a instrução de oficiais, ao longo do ano". Assim, os ensinamentos franceses desceram das alturas da Escola Superior de Guerra até chegar a tenentes e sargentos - a estes, evidentemente, com os devidos cuidados, dada a situação de efervescência política vigente nesses escalões entre 1962 e 1964. A importância da disseminação institucional dessa doutrina para a unificação das forças golpistas parece evidente. Vale reproduzir o testemunho de um oficial que ocupou cargos importantes no regime do pós-64:

\begin{abstract}
No início de 1964, já sentíamos que o confronto era inevitável. Do Rio de Janeiro, em suas novas funções, o general Taurino mantinha conversações com seus pares. Em carta que me enviou, de próprio punho, o general Taurino dava notícia de um memorial a ser dirigido ao Presidente da República, por intermédio do ministro da Guerra, e que seria assinado por todos os generais da ativa dispostos a expressar sua preocupação com os rumos que a nação estava tomando.
\end{abstract}

\section{E continua:}

No Estado-Maior do Exército, seu chefe, o general Castello Branco, encerrara um novo simpósio sobre Guerra Revolucionária. Comunicando-me o evento, o coronel Curvo dizia-me que o encerramento fora "a portas fechadas e com aviso prévio de que o assunto seria secreto, com recomendações de não se comentar o assunto". O coronel Curvo me adiantava, porém, que "o general Castello botara o dedo na moleira, falando claramente sobre o que estava acontecendo no país" (Passarinho, 1996, p. 176).

\section{A ação psicológica: o público externo}

O progressivo fechamento interno foi acompanhado pela abertura da ação psicológica ao público civil, como parte da ação psicológica golpista. Assim, a partir de 1961, começam a ser publicados livros e panfletos destinados a um público mais amplo, cujo primeiro exemplo foi, talvez, Democracia e comunismo, coletânea de artigos extraídos de $A$ Defesa Nacional, editada como "publicação autorizada pelo Estado-Maior do Exército", sem indicação de editora ou local de publicação. Já em 1964, o folheto de 54 páginas, Livro Branco sobre a guerra revolucionária no Brasil, reproduz quase literalmente as discussões militares sobre a doutrina francesa - técnicas destrutivas, técnicas construtivas, fases de desenvolvimento, guerra psicológica, parada e resposta etc. - para em seguida demonstrar, numa longa lista de trinta e oito episódios relativos às greves e crises do período, que a guerra revolucionária já existia no país. ${ }^{7}$

O fundamental nesse sentido é o trânsito das idéias de dentro para fora das Forças Armadas, o que contraria teses até hoje muito influentes que enfatizam a dependência intelectual e política dos oficiais conservadores em relação a seus aliados civis. Não por acaso, em outubro de 1961, ao substituir 
na chefia do Estado-Maior das Forças Armadas o general Oswaldo Cordeiro de Farias, o general Osvaldo de Araújo Mota apresentou a questão de forma um tanto cifrada:

\begin{abstract}
A política social do mundo influi na doutrina militar a eleger e determinar uma atitude a manter. Assim, se não nos faltam a nós, militares, inteligência, observação e conhecimentos, para formular, oportunamente, aquele conceito, dentro de nossas reais possibilidades e dos compromissos internacionais, não nos deve faltar e nos conforta saber que não nos faltará a constante vigilância de uma ideologia e a contaminação de uma doutrina, que, cerceando a liberdade e ameaçando a paz, repugna o espírito cristão de nossa gente (Apud Carone, 1985, pp. $177-178){ }^{8}$
\end{abstract}

A frase tem sintaxe confusa, mas sentido claro. Inteligência, observação e conhecimentos tinham levado os militares a buscar em suas próprias doutrinas a justificativa para a intervenção na política. A crise da renúncia e a posse de Goulart sob um regime parlamentarista, a volta do presidencialismo e o debate sobre as reformas de base, tudo isso serviu para confirmar as visões doutrinárias sobre o avanço da guerra revolucionária no Brasil.

Faltava apenas traduzir a árida linguagem dos documentos militares para o mundo civil, se possível com o brilho da retórica parlamentar. No início de 1964, isso se fez pela voz do presidente da União Democrática Nacional (UDN), o partido mais importante da oposição a Goulart — e o mais próximo dos militares. Assim, embora a crônica política da época insistisse em que "o Sr. Bilac Pinto, Presidente da UDN, assegura que restringe seus contatos à exclusiva área política civil, jamais mantendo conversas com generais ou outras patentes das Forças Armadas" (Castello Branco, 1975, p. 146), em discurso proferido na Câmara dos Deputados a 23 de janeiro de 1964, ele conjurou os heróis intelectuais dos militares para aguçar seus argumentos contra o que considerava o avanço do golpismo do presidente da República e de seu cunhado, o deputado federal Leonel Brizola. Sem maiores escrúpulos, citou profusamente nomes e fontes militares já nossos conhecidos. Em seu pronunciamento de janeiro de 1964 e nos que fez em seguida, a guerre révolutionnaire saiu dos círculos militares e entrou diretamente, como arma da guerra psicológica, no processo de agitação civil-militar que desembocou no golpe. ${ }^{9}$

Tudo indica que o oficial de ligação entre a cúpula do Exército e a ala mais radical da UDN foi o general Antonio Carlos Murici. De todo modo, o jornalista Carlos Castello Branco, do Jornal do Brasil, dizia em nota publicada no mesmo dia em que o parlamentar faria seu primeiro discurso sobre o tema na Câmara: “O sr. Bilac Pinto, cuja atualização em matéria de terminologia política é louvada pelo sr. Pedro Aleixo, está com a pasta abarrotada de literatura sobre a guerra revolucionária. São Livros de Mao Tsé-Tung sobre guerrilhas, estudos do Estado-Maior do Exército brasileiro, revistas militares norte-americanas e uma tese do general Murici [...]" (Idem, p. 168).

A leitura da série de discursos de Bilac Pinto sobre a guerra revolucionária em curso no Brasil permite supor que a pasta do deputado continha justamente os documentos que analisamos neste artigo. $\mathrm{Na}$ abertura de sua primeira intervenção na Câmara, o líder da UDN, conspirador histórico e aliado antigo da corrente militar conservadora (Skidmore, 1982, p. 283), alegou que "estudos de oficiais superiores das nossas Forças Armadas, a respeito da marcha da guerra revolucionária no Brasil" tinham despertado sua "apreensão relativamente à normalidade da vida constitucional do país" (Pinto, 1964, p. 63). A partir daí, o parlamentar usou livremente os teóricos franceses como fonte para sua pregação já francamente golpista.

Nesse sentido, o argumento central do discurso de 23 de janeiro era de que a guerra revolucionária entrara em sua fase aguda no Brasil, a terceira etapa da escala criada pelo coronel J. Hogard, do Exército francês. ${ }^{10}$ Com olhos na divulgação de seu pronunciamento na imprensa, assegurada pelo apoio de grandes jornais à mobilização golpista, Bilac Pinto descreveu em detalhe as cinco fases de Hogard, na versão que recebeu de um artigo militar recém-publicado. ${ }^{11}$ Em seguida, apresentou documentos referentes aos "grupos dos onze" de Leonel Brizola como prova de que as duas etapas da GR - consolidação da infra-estrutura e organização da rede de resistência - já tinham sido vencidas. Diante disso, citando outro texto militar (Idem, p. 68), ele pregou a necessidade de organizar os civis da frente anticomunista.

Ao mesmo tempo, com base em denúncia que ele próprio formulara em entrevista amplamente divulgada nos maiores jornais do país, o deputado afirmou que o governo estava fornecendo armamentos aos sindicatos - para uso no momento do golpe comunista que se preparava (Idem, p. 71). ${ }^{12}$ 
Isso fundamentou seu diagnóstico de que o Brasil já ingressara na terceira etapa da guerra revolucionária, que ele complementou com os seguintes traços: "1) ampla infiltração comunista em todos os escalões do governo; 2) infiltração comunista nas Forças Armadas; 3) ampla e ostensiva infiltração comunista nos partidos". A tudo isso ele acrescia a "promoção de greves, com motivação política ostensiva" e o "controle das organizações estudantis e trabalhistas". Seu argumento final vinha em seguida: no Brasil, a guerra psicológica estava em estado avançado e sua mensagem central eram as reformas de base (Idem, pp. 73-76).

\section{Depois do golpe}

Nos primeiros anos após o golpe militar de 31 de março de 1964, há evidências de que a doutrina francesa permaneceu como ponto de referência no interior das Forças Armadas. Exemplo de tal continuidade foi o relatório final do Inquérito Policial Militar (IPM) número 709, que investigou o comunismo no Brasil. Redigido em maio de 1966 e publicado em fevereiro de 1967, em quatro volumes, pela Biblioteca do Exército, dedicava o seu último tomo à "Ação violenta", com ênfase na evolução da guerra revolucionária nos anos de 1960. O documento partia da idéia-força de que "Guerra Revolucionária é a ação comunista pela conquista do mundo" (IPM 709, 1967, p. 7), procurando enfatizar a centralidade atribuída pelos comunistas às guerras de libertação nacional como principal frente de atuação comunista e salientando a importância que o PC soviético conferia à América Latina, como palco da revolução mundial depois da vitória da Revolução em Cuba, em janeiro de 1959.

Ao mesmo tempo, continuaram as discussões sobre o tema no âmbito do Estado-Maior das Forças Armadas. Foram também incorporadas as mudanças ocorridas no seio do Movimento Comunista Internacional (MCI) na segunda metade dos anos de 1960. A conceituação básica permanecia a mesma: definia-se a Guerra Revolucionária como "um processo permanente de subversão, conduzido por uma adestrada minoria comunista, infiltrada nos principais setores da estrutura administrativa e social dos países democráticos, visando à sua desagregação e substituição por uma sociedade comunista" (Estado-Maior das Forças Armadas, 1969, p. 2). Mas o EMFA reconhecia que as divergências no MCI implicavam na presença de estratégias revolucionárias diversas: "Enquanto Moscou prega a conquista do poder por meios pacíficos - política de coexistência pacífica, Pequim clama que somente a guerra conduzirá à verdadeira 'Revolução Mundial”' (Idem, p. 12). Por sua vez, o texto opunha Régis Debray, que via a guerrilha como desencadeador de guerra revolucionária, a Mao Tse-tung e Guevara, considerando ambos como partidários da eclosão das guerrilhas apenas em condições favoráveis. Enfim, o documento reconhecia o debate em curso na esquerda sobre o cenário mais favorável à guerrilha, o campo ou a cidade (Idem, pp. 25-26).

Mas o mais significativo no texto de 1969 era sua tentativa de simplificar o esquema das etapas da guerra revolucionária, abandonando o já mencionado quadro das cinco etapas proposto por Hogard e centrando-se numa divisão mais simples que propunha dois momentos principais: o da preparação e o da execução. Como se vê no Quadro, a eclosão de ações terroristas e o desencadeamento da guerrilha rural e urbana - que ocorreram no Brasil a partir de 1968 - eram considerados os sinais da passagem da fase de preparação para a de execução da guerra revolucionária. Estava dado, assim, o sinal verde para o envolvimento direto das Forças Armadas na repressão à luta armada de esquerda.

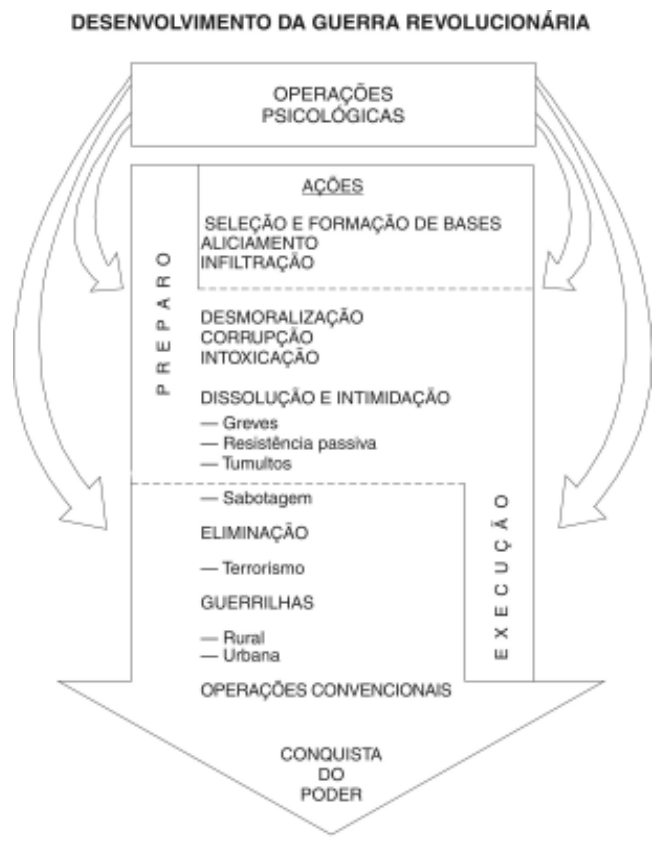

Fonte: EMFA (1969), c-20-69. 
Nesse sentido, o documento do EMFA de 1969 sobre a guerra revolucionária afirma que "as ações repressivas não significam, obrigatoriamente, a aplicação da expressão militar. Somente em casos de grave perturbação da ordem interna é que caberá às Forças Armadas atuar contra as forças da subversão; embora ações militares de apoio a outras expressões do poder possam fazer-se necessárias desde os estágios iniciais do movimento" (Idem, p. 29). Tudo indica que o seqüestro do embaixador norte-americano Elbrick foi o divisor de águas, o caso de "grave perturbação da ordem interna" que conduziu inequivocamente à decisão militar de assumir o controle e o comando das operações contra a guerrilha urbana.

\section{Notas}

1 O primeiro autor a citar, em artigo de 1988 (pp. 238239), a influência da doutrina francesa no Brasil dos anos de 1960 foi Eliezer Rizzo de Oliveira. Seguiramse Joaquim Xavier da Silveira (1989, p. 264), o depoimento do general Octávio Costa aos pesquisadores do CPDOC (D'Araujo et al., 1994, pp. 77-78), Geraldo Cavagnari (1994, p. 47), Rodrigo Patto Sá Motta (2002, p. 261) e Élio Gaspari (2003, pp. 86-87, 105, 135). Esses autores, porém, não desenvolveram o tema.

Outra fonte aponta no mesmo sentido. Em A FEB por um soldado, Joaquim Xavier da Silveira dizia: "os centros de estudos militares brasileiros passaram a atentar para esse novo fenômeno social-militar, o que talvez venha a explicar o movimento antiinsurrecional de março de 1964. A tão decantada influência americana, nesse movimento político-militar, foi praticamente nula. O historiador do futuro, no exame sereno desse episódio, irá certamente encontrar uma certa influência francesa, pelo menos no campo doutrinário" (Silveira, 1989, p. 264). Agradeço a Amanda Mancuso a menção a essa fonte.

3 Não espanta, assim, que em maio de 1959, o coronel Augusto Fragoso assim explicasse à sua audiência da Escola Superior de Guerra brasileira: "a bibliografia francesa sobre a GR é, pode-se dizer, a única existente. A bibliografia de origem norte-americana não deu até agora ao assunto a importância merecida: nos catorze últimos números consultados da Military Review (de janeiro de 1958 a fevereiro de 1959) não há nenhum estudo, artigo ou tópico que fale, no título, de Guerra Revolucionária, Guerra Insurrecional ou Guerra Subversiva" (Estado-Maior da Forças Armadas, 1959, p. 5).

4 Publicado no Brasil, em 1963, pela Biblioteca do Exército em parceria com a editora de esquerda Civilização Brasileira, em tiragem de 9 mil exemplares, particularmente alta para a época.
5 O curso foi reproduzido em Estado-Maior da Aeronáutica (1963), com acréscimo de uma importante diretriz do general Humberto de Alencar Castello Branco.

6 Note-se a caracterização do episódio do levante comunista como "revolução", para adaptá-lo melhor à doutrina francesa, e não "intentona comunista", termo oficial do discurso militar.

7 O texto encerra-se com um apelo: "Faz este livro circular".

8 Citado a partir de matéria de $O$ Estado de S. Paulo, de 17/10/1961.

9 Para a repercussão dos discursos, ver Carone (1985, p. 203).

10 Uma evidência de que essas idéias ainda eram desconhecidas dos civis é o erro na grafia do nome do coronel francês J. Hogard, em artigo do tão bem informado Carlos Castello Branco: "terceira etapa na seriação formulada por Togard" (1975, p. 168, grifo do autor).

11 "Tenho em mãos o estudo do Tenente-Coronel Antônio Fonseca Sobrinho, publicado pelo Estado-Maior do Exército", explicou o deputado (Pinto, 1964, p. 67).

12 A denúncia mostrou-se depois totalmente infundada e, na ocasião, foi o principal alvo das críticas do líder do governo, o deputado Doutel de Andrade, que exigiu repetidas vezes em plenário que Bilac dissesse onde estavam as armas.

\section{BIBLIOGRAFIA}

ARRUDA, Antonio de. (1980), ESG: história de sua doutrina, São Paulo, GRD/INL-MEC.

CARONE, Edgard. (1985), A República Liberal. II evolução política (1945-1964). São Paulo, Difel.

CASTELLO BRANCO, Carlos. (1975), Introducão à Revolução de 1964, A queda de João Goulart, Tomo 2. Rio de Janeiro, Artenova.

CAVAGNARI FILHO, Geraldo L. (1994) "Estratégia e defesa (1960-1990)". Premissas, 7: 2668, ago. Campinas.

COMBLIN, Joseph. (1980), A ideologia da segurança nacional: o poder militar na América Latina. 3 ed. Rio de Janeiro, Civilização Brasileira.

D'ARAUJO, Maria Celina S. et al. (1994), Os anos de chumbo: a memória militar sobre a repressão. Rio de Janeiro, Relume Dumará.

ESTADO-MAIOR DA AERONÁUTICA. (1963), Noções básicas sobre guerra revolucionária - coletânea, 2 ed. Rio de Janeiro, EMA, out. 
ESTADO-MAIOR DAS FORÇAS ARMADAS. (1959), "Introdução ao estudo da guerra revolucionária", conferência de Augusto Fragoso. Rio de Janeiro, Escola Superior de Guerra.

. (1961), Guerra revolucionária. Rio de Janeiro, EMFA.

(1969) Aspectos da guerra contemporânea: a guerra revolucionária. Rio de Janeiro, Escola Superior de Guerra, Departamento de Estudos, C-20-69.

ESTADO-MAIOR DO EXÉRCITO. (1962), Mensário de Cultura Militar, número especial, ano XV, out.

FITCH, J. Samuel. (1998), The Armed Forces and democracy in Latin America. Baltimore/Londres, The Johns Hopkins University Press.

GASPARI, Elio. (2003), O sacerdote e o feiticeiro: a ditadura derrotada. São Paulo, Companhia das Letras.

IPM 709 (INQUÉRITO POLICIAL MILITAR n. 709). (1967), O comunismo no Brasil. V. A ação violenta, vol. 4. Rio de Janeiro, Biblioteca do Exército Editora.

LÓPEZ, Ernesto. (1988), Seguridad nacional y sedición militar. Buenos Aires, Legaz.

MOTTA, Rodrigo P. S. (2002), Em guarda contra o perigo vermelho. São Paulo, Perspectiva/Fapesp.

OLIVEIRA, Eliezer R. (1988), “A Doutrina de Segurança Nacional: pensamento político e debate estratégico", Politica e Estratégia, VI (2): 233-246, abr.-jun.

PARET, Peter. (1964), French revolutionary warfare: from Indochina to Algeria. Nova York/Washington/ Londres, Praeger.

PASSARINHO, Jarbas. (1996), Um bibrido fértil. Rio de Janeiro, Expressão \& Cultura.

PINTO, Bilac. (1964), A guerra revolucionária. São Paulo, Forense.

SHY, John \& COLLIER, Thomas W. (1986), "Revolutionary war", in Peter Paret (org.), Makers of modern strategy, Princeton, Princeton University Press.

SKIDMORE, Thomas. (1982), Brasil: de Getúlio a Castelo. Rio de Janeiro, Paz e Terra.
(1989), Brasil: de Castelo a Tancredo. Rio de Janeiro, Paz e Terra.

SILVEIRA, Joaquim X. da. (1989), A FEB por um soldado. Rio de Janeiro, Nova Fronteira. 


\section{A INFLUÊNCIA DOUTRINÁRIA FRANCESA SOBRE OS MILITARES BRASILEIROS NOS ANOS DE 1960}

\section{João Roberto Martins Filho}

Palavras-chave: Forças Armadas; Guerra Fria; Governo militar; Teoria da guerra; Golpe de 1964.

Com base em documentos de EstadoMaior, este artigo analisa a importação pelos militares brasileiros de um corpo de idéias gerado na França na segunda metade dos anos de 1950. Trata-se da doutrina conhecida como guerre révolution naire, voltada para a derrota do movimento marxista-leninista e desenvolvida no contexto da Guerra da Argélia. Trazidas para a América do Sul, inicialmente por militares argentinos, as idéias francesas chegaram ao Brasil em 1959, numa conferência pronunciada na Escola Superior de Guerra. A partir de então, foram adotadas como doutrina oficial pelo Estado-Maior das Forças Armadas, ajudaram na campanha de idéias que precedeu o golpe de 1954 e continuaram influentes depois da ruptura do processo constitucional. Ao contrário do que aparece na literatura sobre o tema, autores franceses, e não norte-americanos, teriam sido a fonte principal do pensamento militar brasileiro nos anos de 1960 .

\section{FRENCH DOCTRINAIRE INFLUENCE ON BRAZILIAN MILITARY IN THE 1960s}

\author{
João Roberto Martins Filho
}

Keywords: Armed Forces; Cold War; Military government; Theory of war; The 1964 coup d'état.

Based on official military documents, the article approaches the adoption of French military doctrines by the Brazilian military in the second half of the 1950s. More exactly, the article deals with the doctrine known as guerre révolutionnaire, whose aim was to defeat the Marxist-Leninist movement, in the context of the Algerian War. Brought to South America initially by the Argentine military, the French ideas have landed in Brazil in 1959, thanks to a lecture read at Escola Superior de Guerra. In the following years, they were adopted as official doctrine by the Brazilian Armed Forces Chiefs of Staff (EMFA). They were also used as ideological ammunition in the juncture preceding the military coup d'état of March 1964 and its influence was felt in the years after the coup. Contrary to what is accepted by the mainstream literature, French writers, not American ones, were the main source of Brazilian military ideas in the sixties.

\section{L'INFLUENCE DOCTRINAIRE FRANÇAISE SUR LES MILITAIRES BRÉSILIENS DANS LES ANNÉES SOIXANTE}

\author{
João Roberto Martins Filho
}

Mots-clés: Forces Armées; Guerre Froide; Gouvernement militaire; Théorie de la guerre; Coup d'État de 1964.

Ayant pour base des documents de l'État Major, cet article analyse l'importation, par les militaires brésiliens, d'un ensemble d'idées nées en France dans la seconde moitié des années 1950. Il s'agit de la doctrine connue sous le nom de guerre révolutionnaire, tournée vers la défaite du mouvement marxiste-léniniste et développée dans le contexte de la Guerre d'Algérie. Transposées initialement en Amérique du Sud par des militaires argentins, les idées françaises sont arrivées au Brésil en 1959, à l'occasion d'une conférence prononcée à l'École Supérieure de Guerre. À partir de lá, ces idées ont été adoptées comme doctrine officielle par l'État Major des Forces Armées; elles ont aidé à la campagne d'idées qui a précédé le coup d'État de 1964 et ont continué à avoir de l'influence après la rupture du processus constitutionnel. Contrairement à ce qui apparaît dans la littérature sur le sujet, les auteurs français et nord-américains auraient été la source principale de la pensée militaire brésilienne au cours des années 1960. 